\title{
Fifty Nine
}

National Cancer Institute

\section{Source}

National Cancer Institute. Fifty Nine. NCI Thesaurus. Code C105794.

A natural number greater than fifty-eight and less than sixty and the quantity that it denotes. 